\title{
Subcutaneous Aprotinin Causes Local Hyperaemia
}

\section{A Possible Mechanism by which Aprotinin Improves Control in Some Diabetic Patients}

\author{
G. Williams, J.C. Pickup, S. Bowcock ${ }^{1}$, E. Cooke ${ }^{1}$ and H. Keen \\ Unit for Metabolic Medicine, Guy's Hospital and 'Department of Medical Electronics, St. Bartholomew's Hospital, London, UK
}

\begin{abstract}
Summary. Local changes in blood flow at the subcutaneous injection site of the proteinase inhibitor aprotinin and its diluent were measured by photoelectric plethysmography. Aprotinin, but not its diluent, caused local hyperaemia in five normal subjects and in five stable and five brittle insulin-dependent diabetic patients, local blood flow increasing by $80 \%-$ $180 \%$. The duration of the hyperaemic response was shorter in the brittle diabetic patients than in the other two groups, but
\end{abstract}

there was wide individual variation. Aprotinin is known to enhance subcutaneous insulin absorption in normal subjects and in some brittle diabetic patients. The basis for this might be through increasing blood flow near the injection site rather than by inhibition of insulin breakdown.

Key words: Aprotinin, brittle diabetes, subcutaneous blood flow, insulin degradation, photoelectric plethysmography.
Increased subcutaneous insulin degradation is thought to be responsible for very rare cases of massive subcutaneous insulin resistance, in whom increased insulindegrading activity has been demonstrated in subcutaneous adipose tissue [1, 2]. In one case, the insulin-degrading activity was inhibited by the proteinase inhibitor aprotinin [2]. Brittle diabetic patients have an unpredictable response to subcutaneous insulin with wide swings in metabolic control and often show variable resistance to subcutaneous insulin [3]. Significant improvement in glycaemic control by intravenous $[4,5]$ or intramuscular [3] insulin delivery in these patients suggests that they may have a barrier to the absorption of subcutaneous insulin. This barrier has been attributed to subcutaneous insulin degradation following the observation that aprotinin lowers glycaemic levels and insulin requirements in some but not all brittle diabetic patients [5-8]. The insulin-degrading activity of subcutaneous fat biopsy specimens from brittle diabetic patients is not greater than in stable diabetic patients [9]. This suggests that aprotinin, where effective, does not improve subcutaneous insulin absorption by inhibiting insulin degradation and raises the question of an alternative mechanism of action.

This paper reports the local hyperaemic action of aprotinin at the site of its subcutaneous injection in normal subjects and in stable and brittle insulin-dependent diabetic patients.

\section{Subjects and Methods}

Five non-obese, non-diabetic subjects (three male and two female, aged 24-29 years), five stable insulin-dependent and five brittle insulin-dependent diabetic patients were studied. The clinical features of the diabetic patients are shown in Table 1 . All brittle diabetic patients had unpredictable swings in blood glucose and ketone bodies even under supervised and optimised subcutaneous insulin treatment. They also had frequent emergency hospital admissions. No subject had any illness other than diabetes or any evidence of cardiovascular or vasospastic disease and, apart from insulin for the diabetic patients, was taking no medication. Two of the brittle patients had received insulin-aprotinin mixtures therapeutically before referral to Guy's Hospital but had improved clinically. Because of the risk of anaphylaxis [6], we did not attempt to treat any of the other diabetic patients with insulin-aprotinin mixtures. The study was approved by the local Ethical Committee and all subjects gave informed consent.

\section{Photoelectric Plethysmography}

This technique is reviewed by Challoner [10] and has been used previously by us to investigate changes in blood flow close to subcutaneous injection sites [11]. Light shone through the skin from a source in the photoelectric plethysmographic probe is reflected, scattered and absorbed, especially by red blood cells in the illuminated skin and subcutaneous tissue. Its emergent intensity, measured by a photo-detector in the probe, has been shown to be directly proportional to the total blood flow in the illuminated tissue. Changes in the photoelectric plethysmographic signal amplitude reflect changes in blood flow, although absolute measurements cannot be made [10].

\section{Protocol}

All subjects had breakfast, having avoided tea, coffee, cocoa, alcohol and tobacco for at least $12 \mathrm{~h}$ before the test. The diabetic patients had 
Table 1. Clinical characteristics of the diabetic subjects

\begin{tabular}{|c|c|c|c|c|c|c|c|c|c|c|}
\hline & $\begin{array}{l}\text { Case } \\
\text { no. }\end{array}$ & Sex & $\begin{array}{l}\text { Age } \\
\text { (years) }\end{array}$ & $\begin{array}{l}\text { \% Ideal } \\
\text { body } \\
\text { weight }\end{array}$ & $\begin{array}{l}\text { Years of } \\
\text { diabetes }\end{array}$ & $\begin{array}{l}\text { Years of } \\
\text { brittle } \\
\text { diabetes }\end{array}$ & $\begin{array}{l}\text { Daily } \\
\text { insulin } \\
\text { dose }(\mathrm{U})\end{array}$ & $\begin{array}{l}\text { Hyper- } \\
\text { glycaemia } \\
\text { + ketosis }\end{array}$ & $\begin{array}{l}\text { Hypo- } \\
\text { glycaemia }\end{array}$ & $\begin{array}{l}\text { Emergency } \\
\text { hospital } \\
\text { admissions }\end{array}$ \\
\hline Stable & 1 & $\mathrm{~F}$ & 23 & 114 & 10 & - & 54 & - & - & - \\
\hline diabetic & 2 & M & 42 & 92 & 25 & - & 38 & - & - & - \\
\hline \multirow[t]{3}{*}{ subjects } & 3 & $\mathrm{~F}$ & 22 & 106 & 11.5 & - & 96 & - & - & - \\
\hline & 4 & $\mathrm{M}$ & 50 & 94 & 28 & - & 48 & - & - & - \\
\hline & 5 & $\mathrm{~F}$ & 58 & 105 & 12 & - & 52 & - & - & - \\
\hline Brittle & 6 & $\mathrm{~F}$ & 13 & 113 & 6 & 5.5 & $50^{\mathrm{a}}$ & $3 /$ month & $10 /$ week & $10 /$ year \\
\hline diabetic & 7 & $\mathrm{~F}$ & 17 & 116 & 9 & 8.5 & 200 & constant & $2 /$ month & $5+/$ year \\
\hline \multirow[t]{3}{*}{ subjects } & 8 & $\mathrm{~F}$ & 14 & 107 & 3 & 3.5 & $40^{\mathrm{a}}$ & constant & $10 /$ week & - \\
\hline & 9 & $\mathrm{~F}$ & 32 & 96 & 24 & 20 & 60 & $10 /$ month & 5/week & $20 /$ year \\
\hline & 10 & $F$ & 32 & 96 & 15 & 2 & 76 & 2/week & $3 /$ week & $5+/$ year \\
\hline
\end{tabular}

a Insulin given by continuous subcutaneous infusion. Hyperglycaemia was blood glucose $>15 \mathrm{mmol} / 1$ and hypoglycaemia was blood glucose $<3 \mathrm{mmol} / \mathrm{l}$ accompanied by symptoms

their usual morning dose of insulin at a site away from the areas of investigation. Experiments were carried out in a quiet room maintained at $22^{\circ}-25^{\circ} \mathrm{C}$ (maximum temperature variation during a single study $<1 \mathrm{C}^{\circ}$ ). Subjects lay supine with skin temperature probes (Ellab, Stockholm, Sweden) taped lightly to the exposed abdomen, during an initial equilibration period of at least $45 \mathrm{~min}$. When the abdominal skin temperature had become stable, two symmetrical areas of similar temperature $\left( \pm 0.5^{\circ} \mathrm{C}\right)$ were chosen on either side of the abdomen, avoiding obvious lipodystrophy, scars and signs of injection trauma. Photoelectric plethysmographic probes (PH7A with a PA13 Photopulse Adaptor, Medasonics, California) were then attached securely to each area with adhesive tape.

Baseline traces were recorded immediately and $10-15 \mathrm{~min}$ later. A fingerprick capillary blood sample was then taken from the diabetic subjects for determination of the plasma glucose by the glucose oxidase method (Analox GM automatic analyser; Analox Instruments, London, UK). Aprotinin ( $0.15 \mathrm{ml}$; Trasylol, Bayer, FRG; 20,000 kallidogenase-inactivating units $/ \mathrm{ml}$ ) was then injected as close as possible to one probe and $0.15 \mathrm{ml}$ of Trasylol diluent $(0.9 \% \mathrm{v} / \mathrm{v}$ benzyl alcohol in isotonic saline) simultaneously beside the other. All injections were given with $9.5 \mathrm{~mm} 26 \mathrm{G}$ needles pushed in vertically to their full depth.

Skin and room temperature were recorded every $5 \mathrm{~min}$ and photoelectric plethysmographic traces of 1-2 min duration were taken from both injection sites at 2, 5, 10,15,20,30, 45 and $60 \mathrm{~min}$ after the injections. Capillary blood samples were taken at 30 and $60 \mathrm{~min}$ after injection in the diabetic patients.

To assess the reproducibility of the photoelectric plethysmographic response to aprotinin injection, a male non-diabetic subject was subsequently examined on four separate occasions using the same protocol, and the coefficient of variation of the change in signal amplitude was determined at each time-point.

\section{Data Analysis}

Changes in blood flow at aprotinin and diluent injection sites were calculated from the difference between the mean photoelectric plethysmographic signal amplitude (over 50 successive pulses) during the two baseline periods and at each time-point after injection, expressed as a percentage of the baseline value. Statistical evaluation of differences was made by the Wilcoxon rank sum test. Results are expressed as mean $\pm \mathrm{SD}$.

\section{Results}

There were no significant differences between the three groups with respect to room temperature or initial skin temperature (non-diabetic subjects: $32.5 \pm 0.7^{\circ} \mathrm{C}$; stable diabetic subjects: $32.6 \pm 0.4^{\circ} \mathrm{C}$; brittle diabetic subjects: $32.4 \pm 0.6^{\circ} \mathrm{C}$ ). Initial plasma glucose concentrations ranged from 10.0 to $16.3 \mathrm{mmol} / \mathrm{l}$ (mean $13.6 \mathrm{mmol} / \mathrm{l}$ ) in the stable diabetic patients and from 7.0 to $22.0 \mathrm{mmol} / 1$ (mean $12.7 \mathrm{mmol} / \mathrm{l}$ ) in the brittle diabetic patients, with no significant difference between the two groups $(p>0.05)$. Blood glucose concentration showed little change during the studies in all the diabetic patients, except in one brittle patient who became hypoglycaemic (blood glucose falling from $13.6 \mathrm{mmol} / 1$ initially to $1.6 \mathrm{mmol} / 1$ at $60 \mathrm{~min}$ ) and who was treated with oral glucose.

Figure $1 \mathrm{~A}-\mathrm{C}$ shows the mean percentage changes in photoelectric plethysmographic signal amplitude at aprotinin and diluent injection sites in the normal subjects, stable and brittle diabetic patients, respectively. In all groups there was an immediate increase in local blood flow after aprotinin injection, reaching a peak by $2 \mathrm{~min}$. At the diluent site, the smaller immediate rise was followed by a rapid decline to close to baseline values at $20 \mathrm{~min}$. Percentage increases at the aprotinin site were significantly greater than those at the diluent site after $2 \mathrm{~min}$ in all groups, except at $60 \mathrm{~min}$ in the brittle diabetic patients. There was no significant difference in the percentage increases in blood flow at the aprotinin site when groups were compared with each other, except that the 60 min value was significantly less in the brittle diabetic group than in the other two groups $(p<0.05)$, the blood flow having returned to baseline values in three of the brittle diabetic subjects. Two of these patients were those who had previously been given insulin-aprotinin mixtures without clinical benefit. As hypoglycaemia could affect skin and subcutaneous blood flow, the results were re-examined omitting the single brittle patient who became hypoglycaemic during the test, when the statistical significance of the 60-min timepoint differences remained the same.

In the subject examined on a further four occasions, the coefficient of variation of percentage change in sig- 

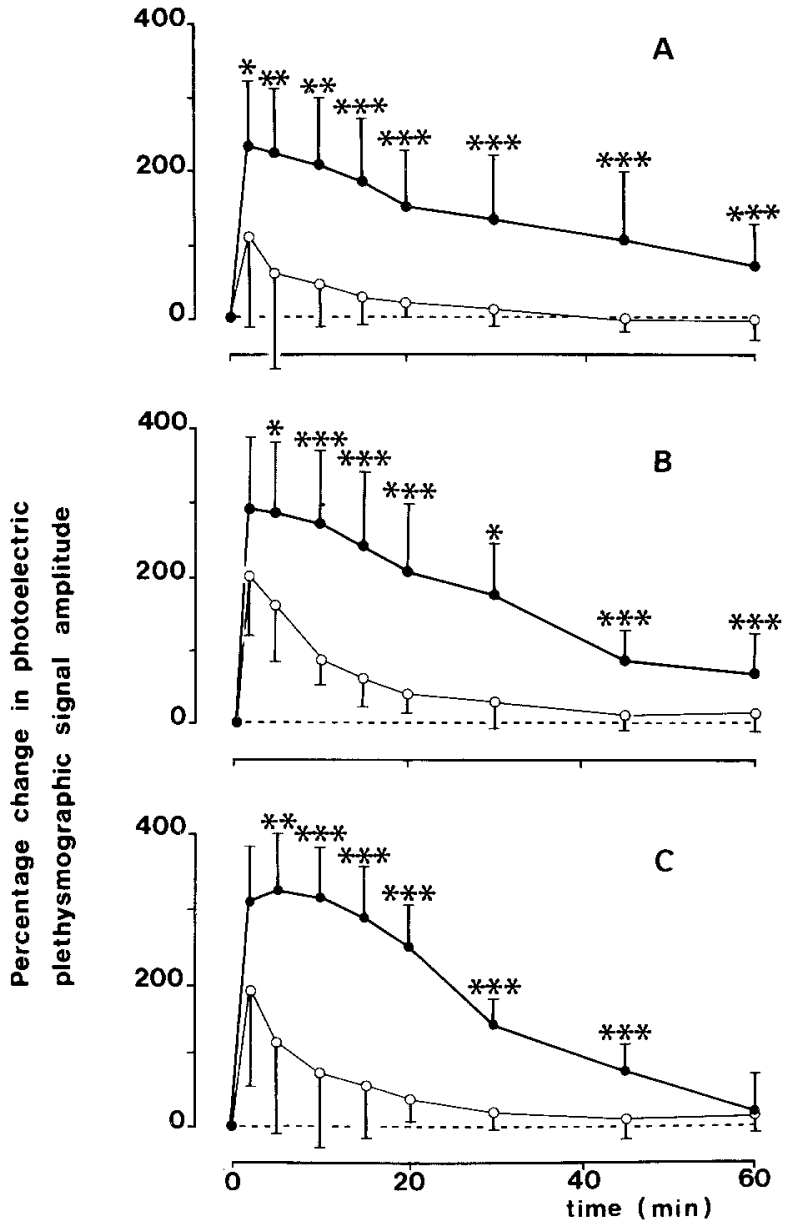

Fig. 1A-C. Percentage changes in photoelectric plethysmographic signal amplitude at injection sites of aprotinin (-O) and of aprotinin diluent $\left(\mathrm{O}_{-} \mathrm{O}\right)$ in $\mathbf{A}$ five normal subjects, $\mathbf{B}$ five stable and $\mathbf{C}$ five brittle insulin-dependent diabetic subjects. Symbols with vertical bars represent mean $\pm \mathrm{SD}$ at each time-point. ${ }^{*} p<0.05$; ${ }^{*} p<0.02$; ${ }^{* * *} p<0.01$ : significance of differences between aprotinin and diluent sites at each time-point

nal amplitude was $14.2 \%$ and $15.1 \%$ at 20 and 30 min respectively, after the initial variable phase had faded. After $45 \mathrm{~min}$, the response was again more variable.

\section{Discussion}

Although there is evidence that increased subcutaneous insulin degradation is the primary defect in the very rare patients with massive subcutaneous insulin resistance $[1,2]$, doubts have recently been raised as to whether this is a major factor influencing insulin absorption and metabolic control in other diabetic patients, particularly those with brittle diabetes $[7,9,12,13]$. Subcutaneous tissue biopsies from brittle diabetic patients whose subcutaneous insulin dose was significantly greater than in stable diabetic patients, showed no greater insulin-degrading activity in vitro than subcutaneous tissue from stable diabetic patients and from normal subjects [9]. Although mixtures of aprotinin and insulin are reported to improve metabolic control and reduce insulin requirements in some diabetic patients who are resistant to high doses of insulin administered subcutaneously [4, $5]$, it is ineffective in other such patients $[7,8]$ as was the case for two of the brittle diabetic patients in this study. In one patient with persistent hyperglycaemia and ketonaemia despite several thousand units of insulin administered subcutaneously per day, aprotinin was ineffective both subcutaneously and intravenously, and also caused anaphylaxis [6]. However, this patient may be different from those with massive subcutaneous insulin resistance and brittle diabetes as she was also resistant to intravenous insulin, having only very low free and total insulin levels despite intravenous administration of up to 20,000 units/day.

Aprotinin has been shown to augment subcutaneous insulin absorption in non-diabetic subjects [14], but has been reported to have no effect in non-insulin dependent diabetic patients [12].

In the present study, the transient hyperaemia at the diluent injection site is similar to that caused by simple needle insertion or injection of saline and weak alcohol solutions [11]. However, the sustained increase in photoelectric plethysmographic signal amplitude seen at the aprotinin injection site suggests that aprotinin causes local hyperaemia when injected subcutaneously into normal and most diabetic subjects. As blood flow is thought to influence insulin absorption [13], aprotinin could therefore accelerate insulin absorption in those subjects who show this response. Impairment of this hyperaemic action might contribute to the failure of some brittle patients to respond clinically to insulin-aprotinin mixtures, as was the case for two of our brittle subjects. Because of the risk of anaphylaxis with repeated use of aprotinin [6], we did not attempt therapeutic trials of aprotinin in any other subjects.

We recently reported [11] that insulin itself injected subcutaneously causes local hyperaemia in normal and stable diabetic subjects, which could assist its own absorption. This hyperaemia is absent in brittle diabetic patients, suggesting that impaired local vascular responses may be the primary cause of brittleness, rather than increased insulin degradation. When effective in brittle diabetic subjects, aprotinin might act by causing local hyperaemia which injection of insulin alone fails to induce in these patients.

Acknowledgements. GW was supported by Novo and JCP by the Medical Research Council. We are grateful to the British Diabetic Association for additional financial support. Dr. S. Tang Fui of Guy's Hospital was of great assistance with the temperature measurements.

\section{References}

1. Paulsen EP, Courtney JW, Duckworth WC (1979) Insulin resistance caused by massive degradation of subcutaneous insulin. Diabetes 28: 640-645

2. McElduff A, Eastman CJ, Haynes SP, Bowen M (1980) Apparent 
insulin resistance due to abnormal insulin degradation: a new mechanism for insulin resistance. Aust NZ J Med 10: 56-61

3. Pickup JC, Home PD, Bilous RW, Keen H, Alberti KGMM (1981) Management of severely brittle diabetics by continuous subcutaneous and intramuscular insulin infusions: evidence for a defect in subcutaneous insulin absorption. Br Med J 282: 347-350

4. Müller WA, Taillens C, Léreret S, Berger M, Philippe J, Halban PA, Offord RE (1980) Resistance against subcutaneous insulin successfully managed with aprotinin. Lancet $1: 1245-1246$

5. Freidenberg GR, White N, Cataland S, D'Orisio TM, Sotos JF, Santiago JV (1981) Diabetes responsive to intravenous but not subcutaneous insulin: effectiveness of aprotinin. New Engl J Med 305: 363-368

6. Pickup JC, Bilous RW, Keen H (1980) Aprotinin and insulin resistance. Lancet 2: 93-94

7. Pickup JC, Williams G, Bilous RW, Keen H (1981) Diabetes resistant to subcutaneous insulin: effect of aprotinin. New Engl J Med 305: 1413

8. Freidenberg GR, Sotos JF, White N, Santiago JV, Cataland S, D'Orisio TM (1981) Diabetes resistant to subcutaneous insulin: effect of aprotinin. New Engl J Med 305: 1414

9. Pickup JC, Williams G, Keen H (1983) Insulin-degrading activity of normal and lipohypertrophic subcutaneous tissue from brittle and stable insulin-dependent diabetics and from normal subjects. Diabetologia 24 (in press)
10. Challoner AVJ (1979) Photoelectric plethysmography for estimating cutaneous blood flow. In: Rolfe P (ed) Non-invasive physiological measurements. Academic Press, New York, pp 125-151

11. Williams G, Clark AJL, Cooke E, Bowcock S, Pickup JC, Keen H (1981) Local changes in subcutaneous blood flow around insulin injection sites measured by photoelectric plethysmography. Diabetologia 21: 516 (Abstract)

12. Deckert T, Hansen B, Lauritzen T, Sandahl Christiansen J (1981) Subcutaneous degradation of insulin. Diabetologia 21: 161-162

13. Lauritzen T, Binder C, Faber OK (1980) Importance of insulin absorption, subcutaneous blood flow and residual beta-cell function in insulin therapy. Acta Paed Scand (Suppl 283): 81-85

14. Berger M, Cüppers HJ, Hegner H, Jorgens V, Berchtold P (1982) Absorption kinetics and biologic effects of subcutaneously injected insulin preparations. Diabetes Care 5: 77-91

Received: 23 February 1982

and in revised form: 8 September 1982

Dr. G. Williams

Unit for Metabolic Medicine

4th Floor, Hunt's House

Guy's Hospital

London SE1 9RT, UK 